\title{
Retrieval of snow albedo and grain size using reflectance measurements in Himalayan basin
}

\author{
H. S. Negi ${ }^{1,2}$ and A. Kokhanovsky ${ }^{2}$ \\ ${ }^{1}$ Snow \& Avalanche Study Establishment, Him Parisar, Sector-37A, Chandigarh 160 036, India \\ ${ }^{2}$ Institute of Environmental Physics, University of Bremen, O. Hahn Allee 1, 28359 Bremen, Germany \\ Received: 18 October 2010 - Published in The Cryosphere Discuss.: 4 November 2010 \\ Revised: 8 February 2011 - Accepted: 18 February 2011 - Published: 11 March 2011
}

\begin{abstract}
In the present paper, spectral reflectance measurements of Himalayan seasonal snow were carried out and analysed to retrieve the snow albedo and effective grain size. The asymptotic radiative transfer (ART) theory was applied to retrieve the plane and spherical albedo. The retrieved plane albedo was compared with the measured spectral albedo and a good agreement was observed with $\pm 10 \%$ differences. Retrieved integrated albedo was found within $\pm 6 \%$ difference with ground observed broadband albedo. The retrieved snow grain sizes using different models based on the ART theory were compared for various snow types and it was observed that the grain size model using two channel method (one in visible and another in NIR region) can work well for the Himalayan seasonal snow and it was found consistent with temporal changes in grain size. This method can work very well for clean, dry snow as in the upper Himalaya, but sometimes, due to the low reflectances $(<20 \%)$ using wavelength $1.24 \mu \mathrm{m}$, the ART theory cannot be applied, which is common in lower and middle Himalayan old snow. This study is important for monitoring the Himalayan cryosphere using air-borne or space-borne sensors.
\end{abstract}

\section{Introduction}

Snow is an important natural resource. Due to high albedo of snow and its large areal extent on the terrestrial surface, it has significant effects on the planetary climate. The snow albedo also influences the rate of melting and, thus it is an important factor for the various activities related to seasonal snowcover. Therefore, many studies have been carried out

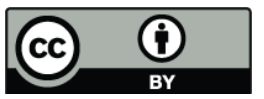

Correspondence to: $\mathrm{H}$. S. Negi

(hs.negi@sase.drdo.in) on albedo measurement and snow cover mapping. The snow grain size and the impurities in snow are known as very important factors for changing the snow albedo (Wiscombe and Warren, 1980; Warren and Wiscombe, 1980; Aoki et al., 2003).

The Himalayan cryosphere has its importance because the presence of vast snow cover in the Himalaya is due to its high elevations, unlike the polar regions and the source of origin for many rivers. Large areas of the Himalaya are covered by seasonal snowfall during winter which starts ablating in the spring, therefore, the areal extent of snow cover changes significantly during winter and spring. The climatic conditions of the Himalaya vary with the mountain ranges, or geographically, which affects the snow metamorphism significantly. Sharma and Ganju (2000) classified the western Himalaya in three different snow climatic zones based on the snow-meteorological data of $25 \mathrm{yr}$ from different field observatories over the western Himalaya and terrain conditions. The upper Himalayan zone is characterised by comparatively low temperatures, light snowfall and severe wind activities. The middle Himalayan zone is characterised by fairly cold temperatures, heavy and dry snowfall with strong wind action. The lower Himalayan zone is characterised by moderate temperatures, heavy snowfall and a short winter period. The study of the albedo and grain size can describe the snow metamorphism, snowmelt and regional climate of the Himalayan regions.

To retrieve the information on snow cover extent from space-borne satellite sensors, it is important to understand the spectral signatures of different types of snow on the ground because of the complex internal structure of snow and inhomogeneity in the snowpack (Massom et al., 2001). The advantages of field spectral measurements can be used in calibration of remote-sensing sensors, predicting the optimum spectral bands for particular application and

Published by Copernicus Publications on behalf of the European Geosciences Union. 
Table 1. Field measured snow parameters at the time of reflectance observations (Not meas. is no measurement recorded).

\begin{tabular}{lccccc}
\hline $\begin{array}{l}\text { Snow type } \\
\text { and date }\end{array}$ & $\begin{array}{c}\text { Time } \\
(\mathrm{LT})\end{array}$ & $\begin{array}{c}\text { Solar zenith } \\
\text { angle }(\text { degree })\end{array}$ & $\begin{array}{c}\text { Snow thickness } \\
(\mathrm{cm})\end{array}$ & $\begin{array}{c}\text { Snow surface } \\
\text { temperature }\left({ }^{\circ} \mathrm{C}\right)\end{array}$ & $\begin{array}{c}\text { Grain size } \\
(\mathrm{mm})\end{array}$ \\
\hline \multirow{4}{*}{ Type-I snow } & $09: 30$ & 63.9 & 27 & -2.0 & $0.0-0.5$ \\
29 January 2005 & $10: 20$ & 57.6 & 27 & -2.0 & $0.0-0.5$ \\
& $10: 45$ & 54.9 & 26 & -1.5 & $0.5-1.0$ \\
& $11: 20$ & 52.2 & 24 & 0.0 & $0.5-1.0$ \\
& $11: 50$ & 51.0 & 23 & 0.0 & $1.0-2.0$ \\
& $12: 20$ & 50.7 & 22 & 0.0 & $1.0-2.0$ \\
\hline \multirow{4}{*}{ Type-II snow } & $09: 20$ & 60.9 & 136 & -1.0 & $1.0-2.0$ \\
19 February 2008 & $10: 10$ & 53.5 & Not meas. & -0.5 & $1.0-2.0$ \\
& $11: 00$ & 47.9 & Not meas. & 0.0 & $1.0-2.0$ \\
& $12: 00$ & 44.6 & Not meas. & 0.0 & $1.0-2.0$ \\
& $13: 00$ & 45.8 & Not meas. & 0.0 & $1.0-2.0$ \\
\hline
\end{tabular}

development/testing of models relating to remote-sensing data (Milton, 1987; Milton et al., 2009). Such systematic study provides the possibility of retrieving snow information from air-borne or space-borne sensors in different spectral regions as well as for the validation of satellite retrieved information.

In the present study, reflectance measurements of different types of snow were collected at nadir viewing and attempts were made to retrieve snow properties, i.e., snow albedo (plane, spherical and spectrally integrated) and snow grain size. The asymptotic radiative transfer (ART) theory was used to retrieve the above snow properties from spectral reflectance and albedo measurement data. A comparison among four different snow grain size models based on the ART theory was made and a suitable model was proposed for the different types of Himalayan seasonal snow. Further the comparisons were made between ART simulated parameters and ground observed snow parameters.

\section{Field measurements}

The field study was carried out in the lower Himalayan zone of the western Himalaya (Fig. 1a). This study area provides ample opportunity to see the variations in snow grain size and albedo in a short span of time due to moderate temperatures conditions, as the albedo reduction varies significantly for snow surface temperatures above $-10^{\circ} \mathrm{C}$ (Aoki et al., 2003). All the field experiments were conducted at three different locations i.e., station-1 (lat. $32^{\circ} 16^{\prime} 21^{\prime \prime} \mathrm{N}$, long. $77^{\circ} 10^{\prime} 58^{\prime \prime} \mathrm{E}$ and alt. $2039 \mathrm{~m}$ ), station-2 (lat. $32^{\circ} 19^{\prime} 03^{\prime \prime} \mathrm{N}$, long. $77^{\circ} 09^{\prime} 20^{\prime \prime} \mathrm{E}$ and alt. $2480 \mathrm{~m}$ ) and station-3 (lat. $32^{\circ} 21^{\prime} 18^{\prime \prime} \mathrm{N}$, long. $77^{\circ} 07^{\prime} 35^{\prime \prime} \mathrm{E}$ and alt. $3050 \mathrm{~m}$ ) of Beas basin as per the availability of different types of snow and field instruments (Fig. 1b). Reflectance measurements of snow were carried out using ASD spectroradiometer in the spectral wavelength range of $350 \mathrm{~nm}-2500 \mathrm{~nm}$ with $3 \mathrm{~nm}$ spectral resolution in VIR and $10 \mathrm{~nm}$ spectral resolution at SWIR region. The spectralon reference surface, which is a nearly perfect Lambertian reflector, was used in the reflectance measurement (Analytical Spectral Devices, 1999). All the reflectance observations were carried out at nadir (i.e., viewing zenith angle was $0^{\circ}$ ) and under clear sky conditions (i.e., direct solar radiation). One complete set of spectroradiometer measurements was carried out within 5-10 min, so that the effect of illumination conditions and atmospheric conditions on the snowpack can be assumed unaltered.

To explore the ART theory for retrieving different parameters from spectral signatures of Himalayan snow, field experiments were made on seasonal fresh snow and old snow data with hourly temporal variations over a plane surface (Fig. 2). For fresh snow, the field experiment was conducted on 29 January 2005 at station-1, on day 1 after the cessation of snow storm. This new snowfall was $10 \mathrm{~cm}$ on top of the existing snowpack and this set of reflectance measurements is termed as "Type-I snow". The old/metamorphosed snow reflectance measurements were carried out on 19 February 2008 at station-2. The previous snowfall that occurred on existing snow buildup was only $3 \mathrm{~cm}$ and 4 days old. This set of observations is named "Type-II snow" in the present study. The snow physical parameters measured at the time of field investigation are given in Table 1. The grain samples were selected from 3-4 places nearby the experimental area and the average maximum equivalent grain diameters (EGD) were measured using crystal gauge with a magnifying hand lens. This method of measuring grain size was found practical at the time of field investigations, although advanced methods can now be found in the literature (e.g., Matzl and Schneebeli, 2006; Painter et al., 2007). 


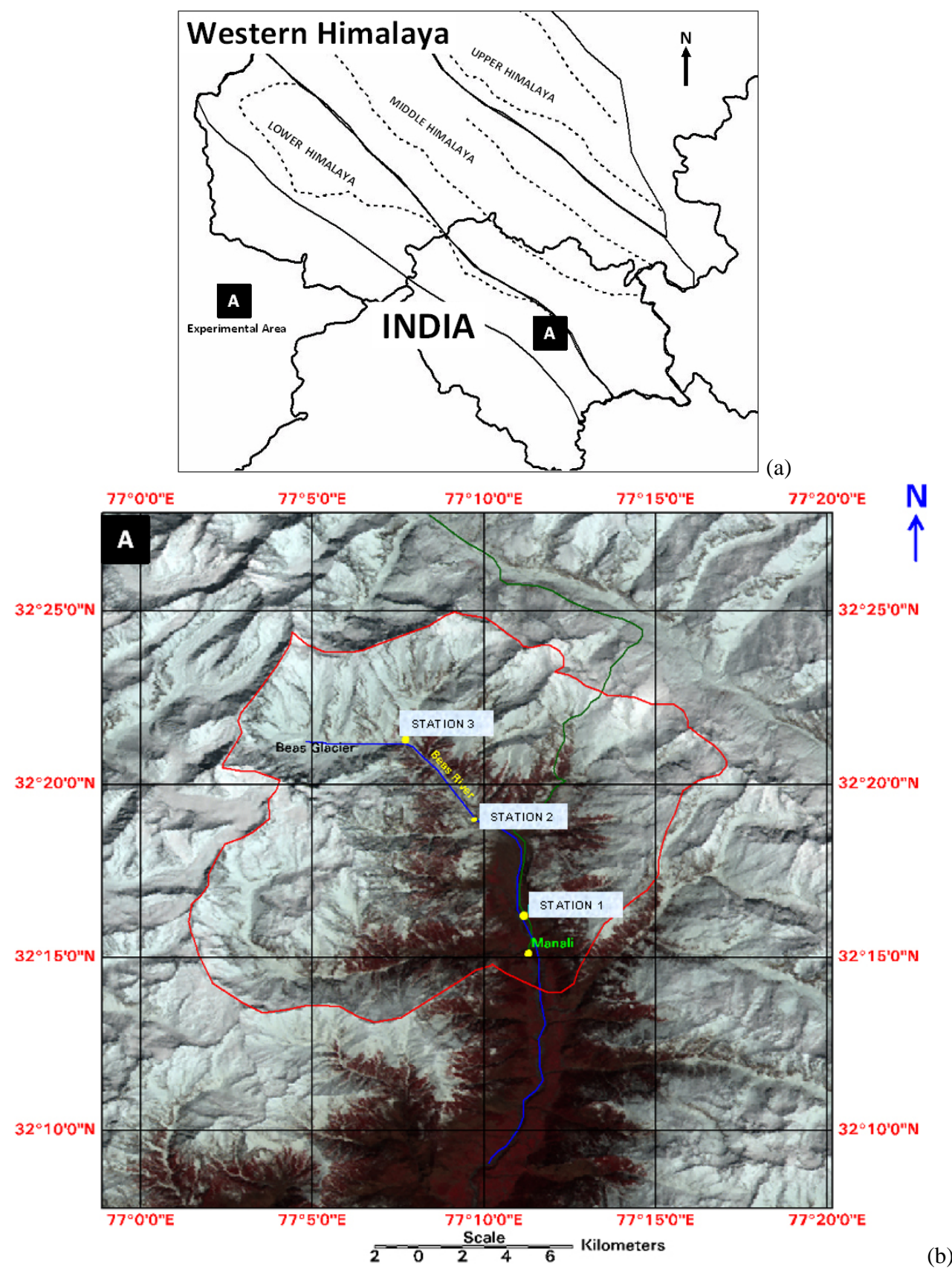

Fig. 1. (a) The map of the western Himalaya comprising three different zones based on the snow climatic conditions, (b) locations of field investigations carried out at station 1-3 in Beas basin of Himalaya.

Spectral albedo measurements were also carried out with each set of reflectance measurements to make the comparison with retrieved spectral albedo using the ART theory (Kokhanovsky and Zege, 2004). The spectral albedo was measured using remote cosine receptor (RCR) connected to the spectroradiometer with fibre-optic cable, by measuring downwelling irradiance followed by upwelling irradiance. Longer wavelengths (beyond $1800 \mathrm{~nm}$ ) were removed from the spectrum due to very poor SNR of the measured spectral albedo. To validate the integrated albedo (i.e., using spectroradiometer) with broadband albedo (using field albedometer), we used another set of observations where we have both the measurements simultaneously just after the snowfall. These experiments were made on 27 and 28 February 2006 in the same basin at station-3. 


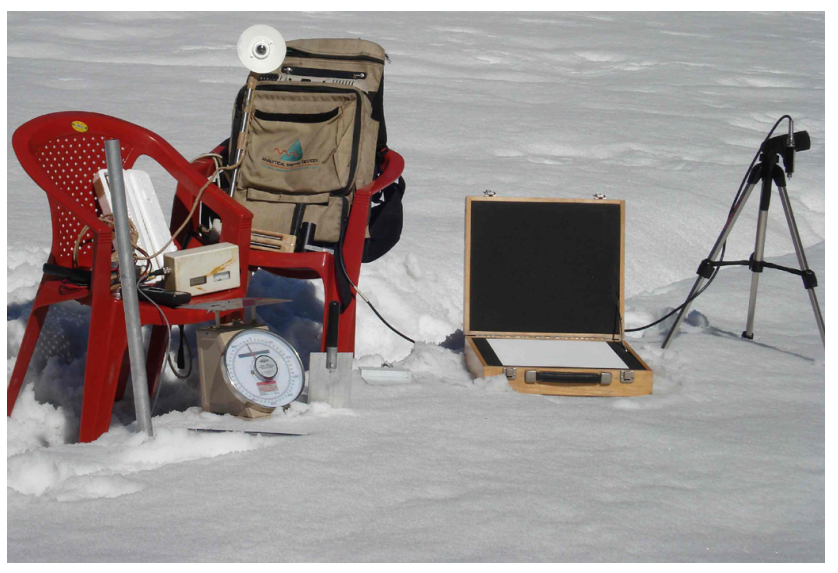

Fig. 2. Field experiment set-up of spectral reflectance measurements (winter 2008).

\section{$3 \quad$ ART theory}

The remote-sensing of snowpack was initially modelled by different researchers (Bohren and Barkstrom, 1974; Warren and Wiscombe, 1980; Warren, 1984) as a layer of dispersed spherical snow grains. The snow retrieval algorithms were made from reflectance characteristics for different satellite data using the model mentioned above (Nolin and Dozier, 1993; Fily et al., 1997; Hori et al., 2001; Li et al., 2001). This model uses Mie theory to obtain single scattering characteristics and radiative theory to relate radiative properties of snow to local snow optical characteristics.

However, snow on the ground consists of irregularly shaped non-uniform snow grains. The optical properties of snow not only controlled by size, but also by the shape of the particles (Mishchenko et al., 1999, 2002; Kokhanovsky, 2003; Kokhanovsky and Zege, 2004). Therefore, more realistic snow models with non-spherical snow grains are proposed by different researchers (Kokhanovsky and Zege, 2004; Zege et al., 2008) and retrievals were made using different satellite sensors (Kokhanovsky et al., 2005, 2011; Tedesco and Kokhanovsky, 2007; Lyapustin et al., 2009; Kokhanovsky and Schreier, 2009). In the present study, this approach has been considered, which introduce the model of snow as fractal grains rather than spherical in order to account for their irregular shape, geometrical optics equations instead of Mie calculations for snow optical characteristics and analytical asymptotic solutions of the radiative transfer theory for snow optical properties (Kokhanovsky and Zege, 2004). According to this theory, snow reflection function can be modelled using an approximate analytical solution in the form of the following equation valid for weakly absorbing snow layers (Kokhanovsky et al., 2003; Kokhanovsky and Zege, 2004):

$$
R\left(\mu, \mu_{0}, \varphi\right)=R_{0}\left(\mu, \mu_{0}, \varphi\right) A^{f\left(\mu, \mu_{0}, \varphi\right)} .
$$

Here $R\left(\mu, \mu_{0}, \varphi\right)$ is reflectance of a semi-infinite snow layer; $\mu_{0}=\cos \vartheta_{0} ; \mu=\cos \vartheta ; \vartheta_{0}, \vartheta$ and $\varphi$ are solar zenith, viewing zenith and relative azimuth angle, respectively. Also it follows:

$A=\exp \{-4 s / \sqrt{3}\}$ and $s=\sqrt{\frac{1-\omega_{0}}{1-g \omega_{0}}}$.

Here $A$ is spherical snow albedo, $\omega_{0}$ is the single scattering albedo and $g$ is the asymmetry parameter. The function $f\left(\mu, \mu_{0}, \varphi\right)$ is given by the following ratio:

$f\left(\mu, \mu_{0}, \varphi\right)=\frac{u\left(\mu_{0}\right) u(\mu)}{R_{0}\left(\mu, \mu_{0}, \varphi\right)}$.

Function $u\left(\mu_{0}\right)$ is called the escape function. It determines the angular distribution of light escaping from the semiinfinite, non-absorbing media and can be approximately given by (Kokhanovsky, 2003):

$u\left(\mu_{0}\right)=\frac{3}{7}\left(1+2 \mu_{0}\right)$.

$R_{0}$ is the reflection function of a semi-infinite snow layer under assumption that the single scattering albedo is equal to one, and $R_{0}$ can be calculated using, the Fourier components of the reflection function in the visible (for a nonabsorbing snow). These are tabulated using a code developed by Mishchenko et al. (1999). The code solves the Ambartsumian nonlinear integral equation for the harmonics $R^{m}\left(\mu, \mu_{0}\right)$ of the reflection function. These harmonics can be stored in LUTs. Thus, the reflection function at any relative azimuth angle is found as:

$R_{0}\left(\mu, \mu_{0}, \varphi\right)=R^{0}\left(\mu, \mu_{0}\right)+2 \sum_{m=1}^{M_{\max }} R^{m}\left(\mu, \mu_{0}\right) \cos (m \varphi)$.

Here $\mu=\cos \vartheta$ and the value of $M_{\max }$ is chosen from the condition that the next term does not contribute more than $0.01 \%$ in the sum (Eq. 5). Alternatively, the function $R_{0}$ can also be calculated using the approximation given by Kokhanovsky (2005):

$R_{0}\left(\mu, \mu_{0}, \varphi\right)=\frac{A+B\left(\mu+\mu_{0}\right)+C \mu \mu_{0}+p(\theta)}{4\left(\mu+\mu_{0}\right)}$,

where $A=1.247, \quad B=1.186, \quad C=5.157, \quad p(\theta)=$ $11.1 \exp (-0.087 \theta)+1.1 \exp (-0.014 \theta), \theta$ is given in degrees and defined as $\theta=\arccos \left(-\mu \mu_{0}+s s_{0} \cos \varphi\right)$. Here $s=\sin (\vartheta)$ and $s_{0}=\sin \left(\vartheta_{0}\right)$.

The theoretical reflectance spectra for a semi-infinite turbid medium can be obtained by solving the nonlinear integral equation derived by Ambartsumian, using the invariance principles. However, such an approach is not suitable for the inverse problem solution because of the computational burden (Kokhanovsky, 2006). Therefore, to make the faster retrievals, the approximate relations have been used for spherical albedo, plane albedo and grain size estimation. 


\section{Retrievals}

The reflection function $R\left(\mu, \mu_{0}, \varphi, \varphi_{0}\right)$ is defined as the ratio of the intensity of light reflected from a snow surface to that of a lambertian surface for a given incident beam direction and observation direction (Kokhanovsky, 2004a, 2006). Thus, $R$ is determined by solar zenith angles $\vartheta_{0}$, viewing angle $\vartheta$, solar azimuth angle $\varphi_{0}$ and viewing azimuth angle $\varphi_{1}$. $R$ is equal to 1 for lambertian surface. Namely it follows:

$R\left(\mu, \mu_{0}, \varphi_{1}, \varphi_{0}\right)=\frac{\pi L\left(\mu, \mu_{0}, \varphi_{1}, \varphi_{0}\right)}{\mu_{0} E_{d}^{\operatorname{dir}}\left(\mu_{0}, \varphi_{0}\right)}$

where $L$ is the upwelling radiance and $E_{\mathrm{d}}^{\mathrm{dir}}$ is the incident direct irradiance. The reflectance measurements carried out during field investigation provide the above function, which was further used to make different retrievals.

\subsection{Albedo}

a. Plane albedo is also called as directional hemispherical reflectance and defined as the integral of reflectance function " $R$ " over all reflection (viewing) angles and can be derived from following equation:

$r_{\mathrm{p}}=\frac{1}{\pi} \int_{0}^{2 \pi} d \varphi \int_{0}^{1} R\left(\mu, \mu_{0}, \varphi\right) \mu d \mu$

where $\mu$ is the cosine of viewing angle and $\varphi$ is the relative azimuth angle.

b. Spherical albedo is also called bi-hemispherical reflectance or diffuse albedo and defined as the integral of plane albedo " $r$," over all solar angles, and can be given by the following equation:

$$
r_{\mathrm{s}}=2 \int_{0}^{1} r_{\mathrm{p}}\left(\mu_{0}\right) \mu_{0} d \mu_{0} .
$$

c. Broadband albedo can be obtained by integrating the plane spectral albedo $r_{\mathrm{p}}(\lambda)$ over the wavelength, weighted by the incident solar flux $F_{\downarrow}(\lambda)$ :

$$
a=\frac{\int r_{\mathrm{p}}(\lambda) F_{\downarrow}(\lambda) d \lambda}{\int F_{\downarrow}(\lambda) d \lambda} .
$$

The albedo defined by Eqs. (8) and (9) are not possible to determine from satellite sensors because measurements are performed with fixed solar and viewing angles. Kokhanovsky et al. (2007) presented an alternative possibility for direct determination of the spherical cloud albedo from single reflection function measurements, for the special case of optically thick cloudiness. This technique requires no a priori information on the particles size and optical thickness. It has also shown that the absolute value of error is below $3 \%$ at optical thickness $\tau \geq 10$ for all considered solar zenith angles and nadir observation, which is suitable in case of snow study.

From Eq. (1), using the ART theory, spherical albedo " $A$ ", can be retrieved from reflection measurements $\left(R_{\text {meas }}=\right.$ $R\left(\mu, \mu_{0}, \varphi\right)$ ) at a fixed geometry and can be given by the following equation:

$A=r_{\mathrm{s}}=\left(\frac{R_{\text {meas }}}{R_{0}}\right)^{1 / f}$.

Thus, spherical albedo can be retrieved by substituting the value of $f$ and $R_{0}$ from Eqs. (3) and (6), respectively. Once we know spherical albedo, the plane albedo can be determined by the following relation (Kokhanovsky, 2002, 2004b):

$r_{\mathrm{p}}=A^{u\left(\mu_{0}\right)}$

or $r_{\mathrm{p}}=\left(\frac{R_{\text {meas }}}{R_{0}}\right)^{R_{0} / u(\mu)}$, where $A$ and $u\left(\mu_{0}\right)$ can be substituted in Eq. (12) from Eqs. (11) and (4).

\subsection{Grain size}

The remote-sensing provides the effective optical size of snow grains, which can be defined by the average volume $V$ and the average projection area $S$ of a snow grain, and can be represented as follows:

$a_{\mathrm{ef}}=\frac{3}{4}(V / S)$,

where $V$ and $S$ represent the particle volume and projected area, respectively (Jin et al., 2008; Kokhanovsky, 2011). In case of monodisperse spheres, $a_{\mathrm{ef}}$ is the same as actual radius. It is possible to determine $a_{\mathrm{ef}}$ using optical measurements on the ground, aircraft or satellite (Dozier et al., 2009), since it has a physical sense, as the snow reflection function is governed mostly by the value of the probability of photon absorption (PPA) (Kokhanovsky et al., 2005). However, it is difficult to measure $a_{\mathrm{ef}}$ with a microscope on the ground, a lot of averaging procedures are required to derive the value of $a_{\text {ef }}$ as given by Eq. (13). The other way to measure $a_{\text {ef }}$ is the specific surface area (SSA), which can be measured by various, direct techniques such as the methane adsorption technique (Legagneux et al., 2002), microtomography (Schneebeli and Sokratov, 2004), near-infrared photography (Matzl and Scheebeli, 2006) and stereology (Matzl, 2006). The relation between SSA and $a_{\mathrm{ef}}$ is given by (Domine et al., 2008):

$\operatorname{SSA}=\frac{\bar{\Sigma}}{\rho_{\mathrm{i}} \bar{V}}$,

where $\rho_{\mathrm{i}}$ is the density of ice $\left(0.9167 \mathrm{~g} \mathrm{~cm}^{-3}\right.$, at $\left.0^{\circ} \mathrm{C}\right)$ and $\bar{\Sigma}, \bar{V}$ are the averaged surface area and average volume with 
respect to the size/shape distributions of grains, respectively. In case of monodisperse spheres SSA can be defined as:

$\mathrm{SSA}=\frac{3}{\rho_{\mathrm{i}} a_{\mathrm{ef}}}$.

Therefore, with the optical measurements of $a_{\text {ef }}$, one can also determine the SSA.

Different authors have used the ART theory to retrieve grain size (Kokhanovsky and Zege, 2004a; Kokhanovsky and Nauss, 2005; Tedesco and Kokhanovsky, 2007; Kokhanovsky and Schreier, 2009). Now this theory has also been used by considering the soot effect in the NIR region in addition to ice absorption (Zege et al., 2008; Kokhanovsky, 2011) and as ratio techniques of different ice absorption channels (Lyapustin, 2009).

a. Single channel method: Kokhanovsky and Zege (2004) first defined the snow grain diameter $(d)$ by physically based equation:

$$
d=\frac{1}{\alpha b^{2} f^{2}} \ln ^{2}\left(\frac{R}{R_{0}}\right),
$$

where $\alpha=4 \pi \chi(\lambda) / \lambda$ is the ice absorption coefficient and $R$ is the measured reflectance at NIR channel. The parameter $b$ depends on the grain shape and asymmetry parameter (considered $\approx 3.62$ for fractal particles; and $\approx 4.53$ for spheres) and other terms are same as mentioned in Sect. 3. In the present study, fractal particles are considered and $R_{0}$ is estimated using the approximation method given by Eq. (6). Imaginary part of ice refractive index $(\chi)$ was used as tabulated by Warren and Brandt (2008).

b. Two channel method: Kokhanovsky et al. (2011) has proposed the two channel method to estimate the grain size and soot concentration using the following equations:

$$
\begin{aligned}
& R_{1}=R_{0} \exp \left(-\gamma \sqrt{\beta_{1}}\right), \\
& R_{2}=R_{0} \exp \left(-\gamma \sqrt{\beta_{2}}\right),
\end{aligned}
$$

where $R_{1}$ and $R_{2}$ are the reflectance in visible and the NIR channel. $\beta_{1}$ and $\beta_{2}$ are PPA in visible (i.e., $0.443 \mu \mathrm{m}$, light absorption due to soot presence) and NIR channel $(0.865 / 1.05 / 1.24 \mu \mathrm{m}$, light absorption due to ice and soot), respectively, and $\gamma$ is given by:

$\gamma=\frac{4 f}{\sqrt{3\left(1-g \omega_{0}\right)}}$.

In the present case, the difference of $\omega_{0}$ from 1.0 in Eq. (19) was neglected. We assume that the PPA in the visible channel $\left(\beta_{1}\right)$ depends only on the soot concentration and not on the size of particles (Kokhanovsky and Zege, 2004). Assuming that there is no dependence of the soot refractive index on the wavelength, one easily derives (Kokhanovsky et al., 2011): $\beta_{2}=$ $\beta_{i, 2}+\lambda_{1} \beta_{1} / \lambda_{2}$, where $\beta_{i, 2}$ is the probability of photon absorption by snow grains. Therefore, it follows from Eqs. (17) and (18):

$\beta_{\mathrm{i}, 2}=\frac{\ln ^{2}\left(R_{2} / R_{0}\right)}{\gamma^{2}}-\frac{\lambda_{1}}{\lambda_{2}}\left(\frac{\ln ^{2}\left(R_{1} / R_{0}\right)}{\gamma^{2}}\right)$.

Subscript 1 and 2 denote the visible and NIR channel, respectively.

Finally, the effective grain radius was defined by Kokhanovsky and Nauss (2005):

$a_{\mathrm{ef}}=\left(K \alpha_{\mathrm{i}, 2}\right)^{-1} \ln \left[\frac{\beta_{\infty}}{\beta_{\infty}-\beta_{\mathrm{i}, 2}}\right]$,

where the value of $K=2.63$ was considered in this study for fractals and $\alpha_{\mathrm{i}, 2}$ is a linear absorption coefficient for ice $\alpha=4 \pi \chi(\lambda) / \lambda$ in the NIR channel. $\beta_{\infty}$ is the limiting case of probability of photon absorption for an ice crystal, which absorbs all radiation penetrated inside the particle (considered $\beta_{\infty}=0.47$ ), and $\beta_{\mathrm{i}, 2}$ can be substituted from Eq. (20).

Kokhanovsky et al. (2011) used LUTs approach, a code developed by Mishchenko et al. (1999) as discussed in Sect. 3, to estimate $R_{0}$, but, presently, we have used the approximation method given by Eq. (6) so that the theory can be used to make fast snow retrievals using inversion technique.

c. Two channel ratio method: Lyapustin et al. (2009) also used the ART theory given by Kokhanovsky and Zege (2004). Instead of the single band they used the band ratio method, where the role of $R_{0}$ reduced to the second order effect manifested in function " $f$ ". They defined the snow grain diameter $(d)$ using two channels with different ice absorption by:

$d=\frac{1}{4 \pi b^{2} f^{2}}\left[\ln \left(\frac{R_{1}}{R_{2}}\right) /\left(\sqrt{\chi_{2} / \lambda_{2}}-\sqrt{\chi_{1} / \lambda_{1}}\right)\right]^{2}$.

This equation is valid for vertically homogeneous snow. Here $R_{1}$ and $R_{2}$ are such that light penetration depth in snow are similar between the two wavelengths, and these can be selected as 1.05 and $1.24 \mu \mathrm{m}$. For inhomogeneous snow, one ice non-absorbing channel $\left(\lambda_{1}\right.$ in visible) and another ice absorbing channel ( $\lambda_{2}$ in NIR) are required. In this case Eq. (22) reduced to:

$d=\frac{\lambda_{2}}{4 \pi \chi_{2} b^{2} f^{2}} \ln ^{2}\left(\frac{R_{1}}{R_{2}}\right)$, 
where $R_{1}$ and $R_{2}$ are the measured reflectance at the visible and NIR channel, respectively. From Eqs. (16) and (23), it can be well observed that the difference is in the logarithmic part where $R_{0}$ is replaced with measured reflectance in visible channel. Lyapustin et al. (2009) has used the radiative transfer code for $R_{0}$, which is used to estimate " $f$ " in Eq. (23). However, in the present study, $R_{0}$ is again estimated from the approximation method (Eq. 6). In this study, the wavelength $0.645 \mu \mathrm{m}$ is selected in the visible instead of $0.443 \mu \mathrm{m}$ because the wavelength closed to channel $0.443 \mu \mathrm{m}$ is more affected by contamination like soil/ash (Negi et al., 2009). Channels $0.645,1.05$ and $1.24 \mu \mathrm{m}$ are used in the combination of $(0.645$ and $1.05 \mu \mathrm{m})$ and $(0.645$ and $1.24 \mu \mathrm{m})$.

d. Three channel method: Zege et al. (2008) defined a new algorithm to retrieve snow grain size and pollution amount from satellite data using three channels reflectance measurement, with no priori snow optical model (i.e., for $R_{0}$ ). They defined the effective size of snow grain by:

$a_{\mathrm{ef}}=\left[\frac{1}{A\left(q_{j}-q_{i}\right) u\left(\mu_{0}\right) u(\mu)}\left(\frac{R_{i}^{q_{j}}}{R_{j}^{q_{i}}}\right)^{\frac{1}{q_{j}-q_{i}}} \ln \left(\frac{R_{i}}{R_{j}}\right)\right]^{2}$,

where $i$ and $j$ are spectral channel, parameter $A$ depends on the shape of the particles and ranges from 3.5 to 6.5 (fractals to spheres; similar as denoted in Eq. (16) by " $b$ ") and $q_{i}$ is given by:

$q_{i}=\sqrt{4 \pi \frac{\left(\chi_{i}+0.2 C_{\mathrm{s}}\right)}{\lambda_{i}}}$,

where $C_{\mathrm{s}}$ is relative soot concentration and $\chi_{i}$ is imaginary part of ice refractive index at visible wavelength $\left(\lambda_{i}\right)$. The analytical solution for estimating $C_{\mathrm{s}}$ is given by Eqs. (14)-(19) of Zege et al. (2008). There is one assumption that the effect of soot pollution on the light extinction in snow is zero. In the present study, channels $R_{2}(0.645 \mu \mathrm{m}), R_{3}(0.859 \mu \mathrm{m}), R_{4}(1.05 \mu \mathrm{m})$ and $R_{5}(1.24 \mu \mathrm{m})$ are used in the combination of $\left(R_{2}, R_{3}\right.$, $\left.R_{4}\right)$ and $\left(R_{2}, R_{3}, R_{5}\right)$.

All the above discussed methods were used for the retrievals of snow grain size and compared. In the present study, the effective grain diameter " $d$ " has been considered as retrieved snow grain size. Further by knowing the " $d$ ", spherical and plane albedo can be retrieved using the approach described by Kokhanovsky and Zege (2004):

$r_{\mathrm{s}}=\exp (-b \sqrt{\alpha} d)$

and

$r_{\mathrm{p}}=\exp \left(-u\left(\mu_{0}\right) b \sqrt{\alpha d}\right)$,

where $b$ is the shape factor and $\alpha$ is the ice absorption coefficient.

\section{Field validation and discussions}

\subsection{Albedo}

The plane and spherical albedo determined from temporal spectral reflectance measurement for Type-I and Type-II snow are shown in Figs. 3 and 4. The difference between the spectral reflectance and albedo is attributed to the presence of snow reflectance anisotropy, as the radiation reflected by snow surface is not distributed uniformly into all angles. An anisotropic reflection function (ARF), is defined by the ratio of reflectance to spectral albedo. It can be observed from Fig. 3 (Type-I snow), the variation of ARF in the NIR region is present throughout (Fig. 3a-f), however, in the visible region this varies with the solar zenith angle (SZA). As the SZA decreases with time for the experiment considered, the difference between reflectance and albedo also decreases in the visible region. In Fig. 3e, at low SZA, when the sun is approximately overhead (i.e., at $1150 \mathrm{~h}$ ), the anisotropy is negligible in the visible region. For (Type-II snow), this anisotropy was observed along the whole spectrum, i.e., visible and NIR region. The presence of anisotropy in the visible region could be explained by impurities in the snow (e.g., clay/dust contamination and soot), as this anisotropy is consistent with respect to spherical albedo observations.

It has been observed that spherical albedo is lower than plane albedo for Fig. 3 (Type-I) and Fig. 4a-b (Type-II), and higher for Fig. 4d-e (Type-II). This difference between the plane and spherical albedo can be attributed by the variation in albedo under diffuse radiation condition explained by Warren (1982), i.e., when SZA greater than $50^{\circ}$ the spherical albedo (i.e., diffused albedo) decreases, however, for SZA below $50^{\circ}$, the spherical albedo increases and remain unaltered around $50^{\circ}$ (Wiscombe and Warren, 1980), which can be observed in the case of Fig. $4 \mathrm{c}\left(\mathrm{SZA} \sim 48^{\circ}\right)$.

The comparison between ART retrieved plane albedo and field measured spectral albedo using spectroradiometer are shown in Fig. 5. It has been observed that the ART retrieved spectral albedos are in good agreement with field measured spectral albedo in NIR region. The departures between simulated and measured albedo in the visible region are attributed to the measuring instrument response, i.e., poor signal-tonoise (SNR) ratio in the visible region. Such difficulties during the measurement of spectral albedo in the field under clear sky conditions are also highlighted by other researchers (Warren, 1982; Warren et al., 1986; Aoki et al., 2000). However, the measurements were carried out over the plane snow surface and leveling of the sensor has been taken care of during the observations. Secondly, in Fig. 4a-c, the measured spectral albedo in the visible region should not decrease for a new snow (Type-I). The comparison of simulated temporal albedo for snow Type-I and Type-II shows an agreement within $10 \%$ differences in measured albedo at wavelength $1.05 \mu \mathrm{m}$ and $1.24 \mu \mathrm{m}$ (Fig. 6). 

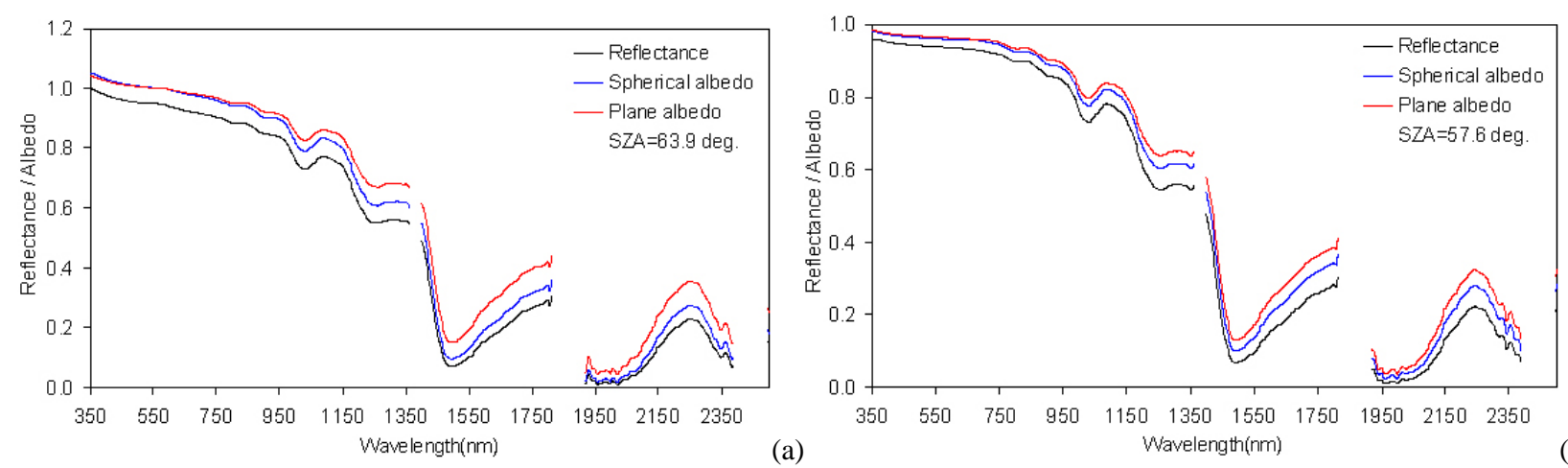

(b)
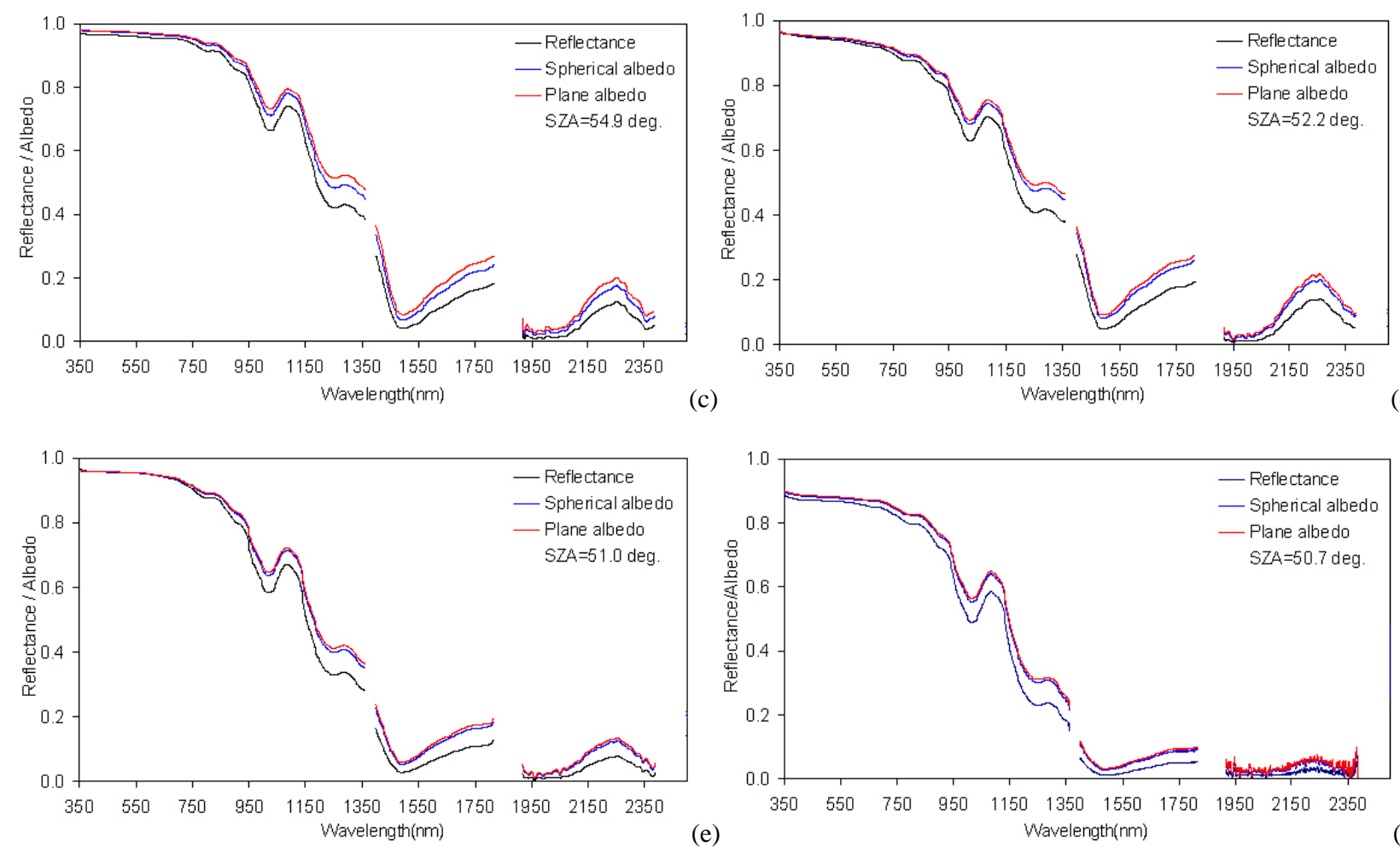

Fig. 3. Field measured reflectance for snow Type-I (new snow) and simulated spherical and plane albedo; (a) 09:30, (b) 10:20, (c) 10:45, (d) 11:20, (e) 11:50 and (f) 12:20 local time.

The integrated albedo was estimated using the field measurement of spectral albedo (i.e., using RCR) and simulated plane albedo, and compared with diurnal variation of direct broadband albedo measurements (Fig. 7). Liu et al. (2009) and Wang and Zender (2010) have also observed the similar trends of dependence of snow albedo with solar zenith angle. Figure $7 \mathrm{a}$ and $\mathrm{b}$ show that integrated albedo data from spectroradiometer (direct measurement and simulated from reflectance) are close to broadband data. Generally, all the integrated albedo using direct measurement, have slightly smaller values than simulated integrated albedo from reflectance data; this also proves the systematic error in our measured spectral albedo data in the visible region. The retrieved integrated albedo was found within $\pm 6 \%$ difference from ground observed broadband albedo. The coefficient of correlation between broadband and integrated albedo using spectral measurements was 0.89 with standard difference (RMSD) 0.028 (Fig. 8a), however, it was improved for integrated retrieved albedo using reflectance, i.e., 0.94 with RMSD 0.020 (Fig. 8b). This indicates that the albedo simulated form reflectance data, using the ART theory, can work well for Himalayan snow.

\subsection{Grain size}

The field reflectance measurement data in $R_{1}(443 \mathrm{~nm}), R_{2}$ $(645 \mathrm{~nm}), R_{3}(859 \mathrm{~nm}), R_{4}(1050 \mathrm{~nm})$ and $R_{5}(1240 \mathrm{~nm})$ channels for retrieving grain sizes by different models are given by Fig. 9a and $\mathrm{b}$ for snow Type-I and Type-II, 

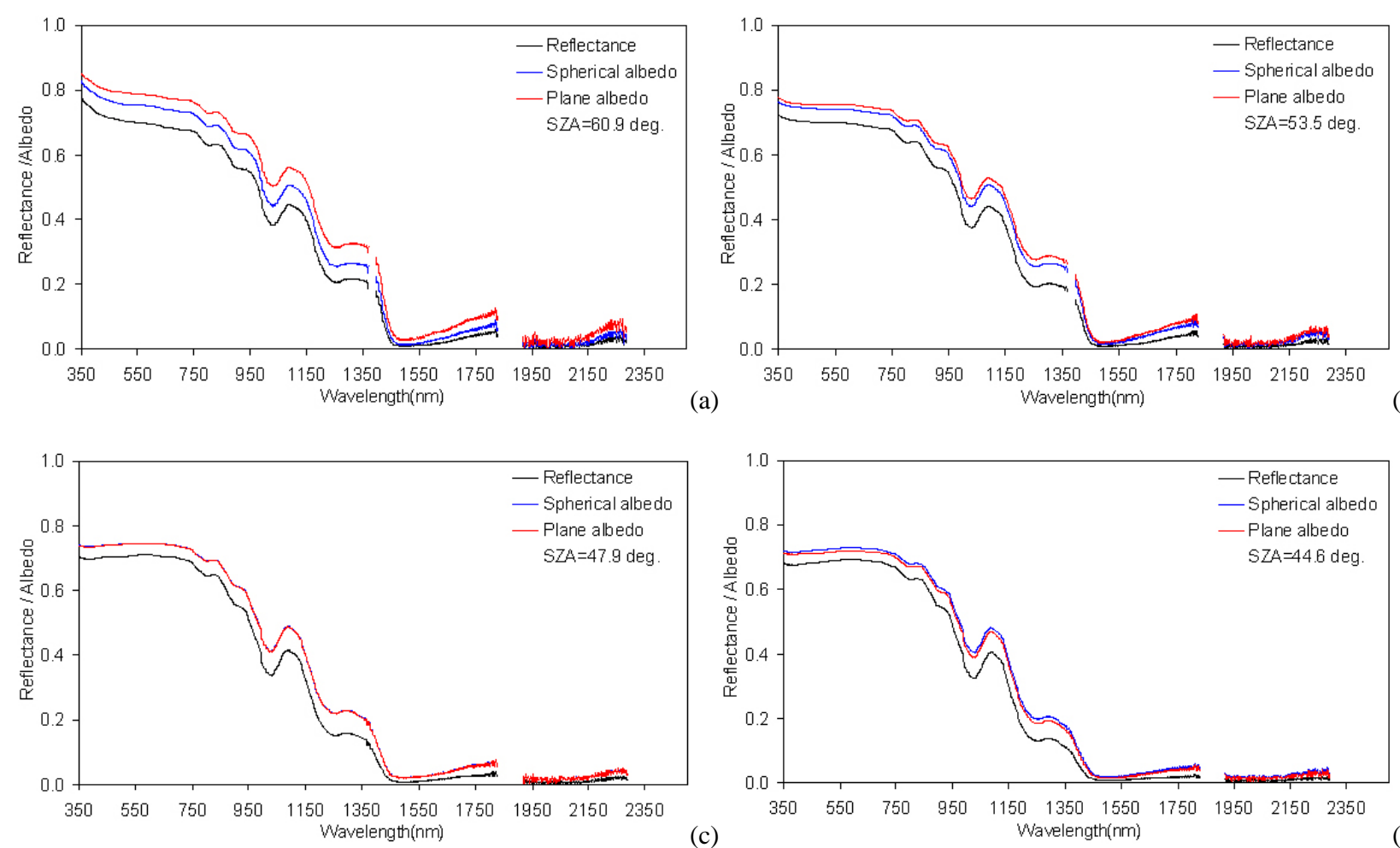

(d)

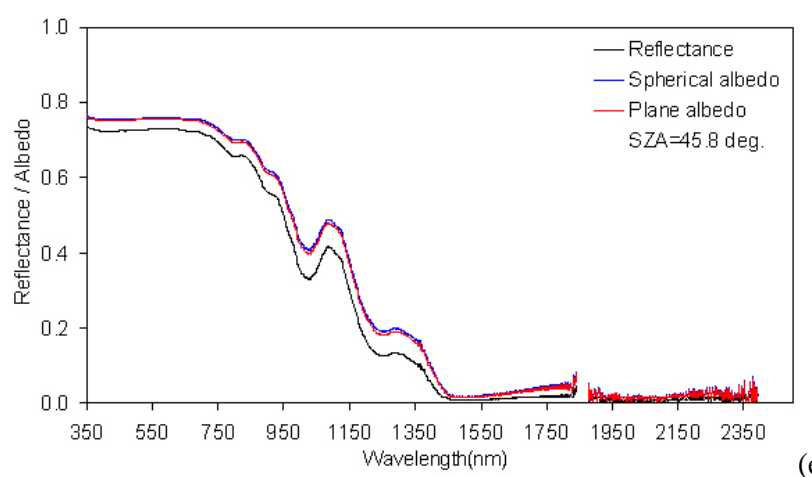

Fig. 4. Field measured reflectance for snow Type-II (old snow) and simulated spherical and plane albedo; (a) 09:20, (b) 10:10, (c) 11:00, (d) 12:00 and (e) 13:00 local time.

respectively. A slight variation in reflectance can be observed in $R_{1}, R_{2}$ and $R_{3}$ channels due to variations in atmospheric and snow conditions with time under natural field environment, but for $R_{4}$ and $R_{5}$ decreasing trend was observed, which was attributed to the increasing trend of snow grain size. Field measured parameters (Table 1) also indicate temporal increasing in grain size for both types of snow, as the snow grain size increases due to clustering of snow grains at snow temperature close to $0^{\circ} \mathrm{C}$ (Colbeck, 1982). For snow Type-II, the reflectances at $R_{5}(1240 \mathrm{~nm})$ are less than 0.2 , where the ART theory fails, as the theory is only valid for semi-infinite media with low absorption (Kokhanovsky and Zege, 2004) and, therefore, grain size was not retrieved for such low reflectances.
The grain size retrievals were made using four methods as discussed in Sect. 4.2 and shown by Table 2. The retrieved grain size for snow Type-I were underestimated as compared to ground-measured snow grain sizes in the first three methods. This suggests that the ground measured grain size, i.e., maximum equivalent grain diameter, is not a correct measurement. Aoki et al. (2000) also reported after observing three types of grain equivalent measurements on the ground and found that effective grain size falls in the range of measured lengths of narrower portions of broken crystals. Unfortunately, we could not make such fine level length measurements using field instruments available to us for new snow, however, as the snow become rounded due to metamorphism, the retrieved grain sizes are in agreement with the measured 

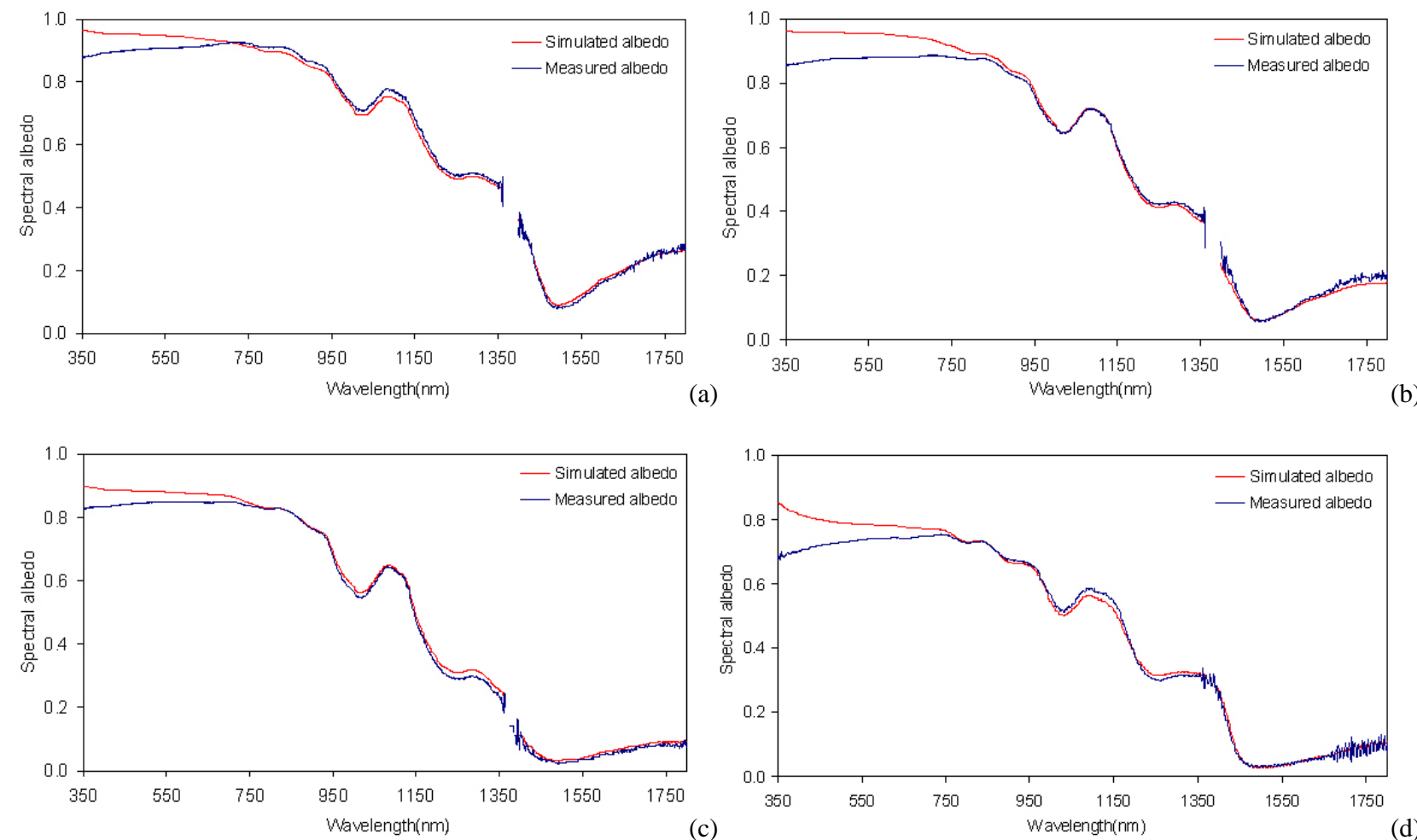

(b)
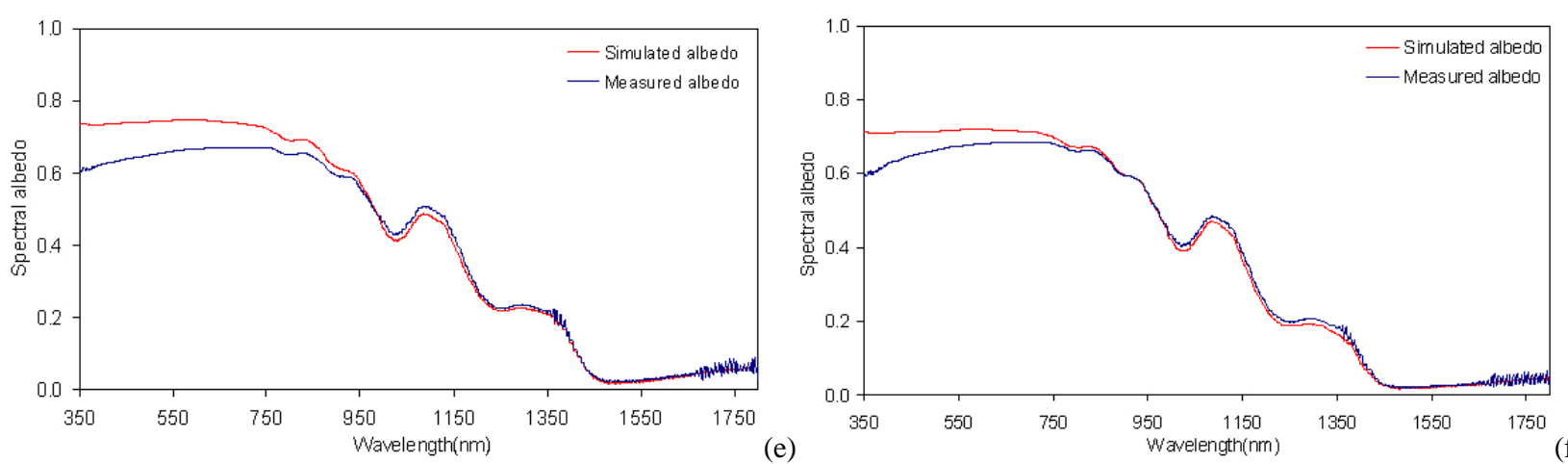

Fig. 5. The comparison between simulated plane albedo and field measured spectral albedo; (a-c) are for snow Type-I at 11:20, 11:50 and 12:20 local time, and (d-f) are for snow Type-II at 09:20, 11:00 and 12:00 local time, respectively.
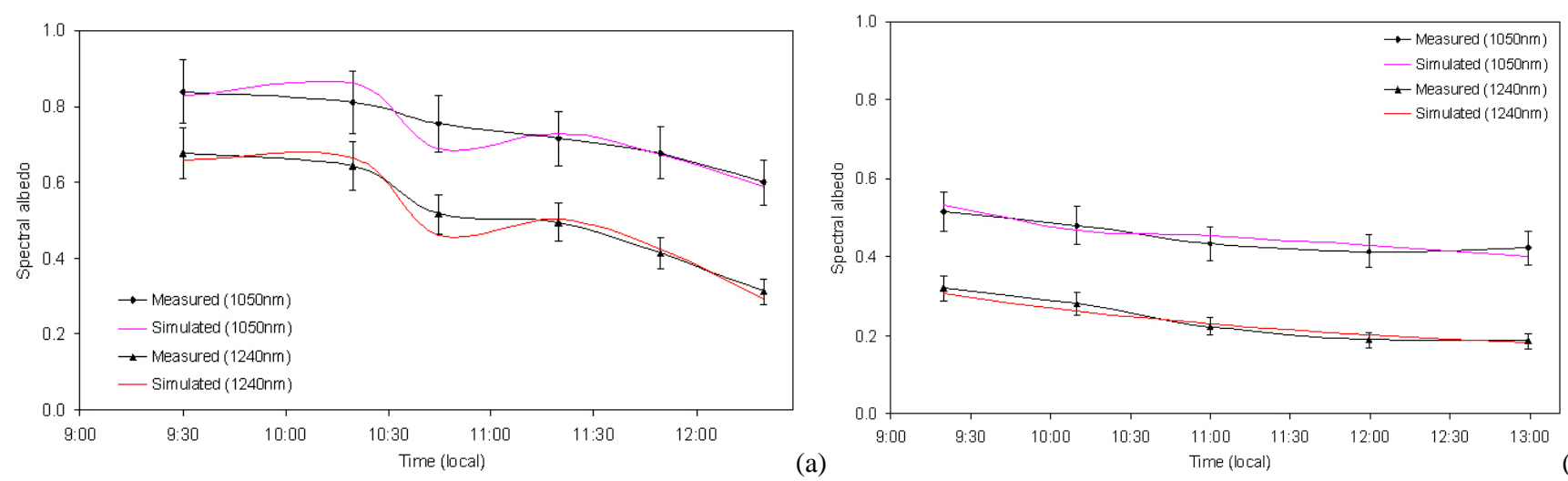

(b)

Fig. 6. The comparison between simulated temporal plane albedo and field measured spectral albedo with $10 \%$ differences at wavelength $1.05 \mu \mathrm{m}$ and $1.24 \mu \mathrm{m}$ for (a) snow Type-I and (b) snow Type-II. 

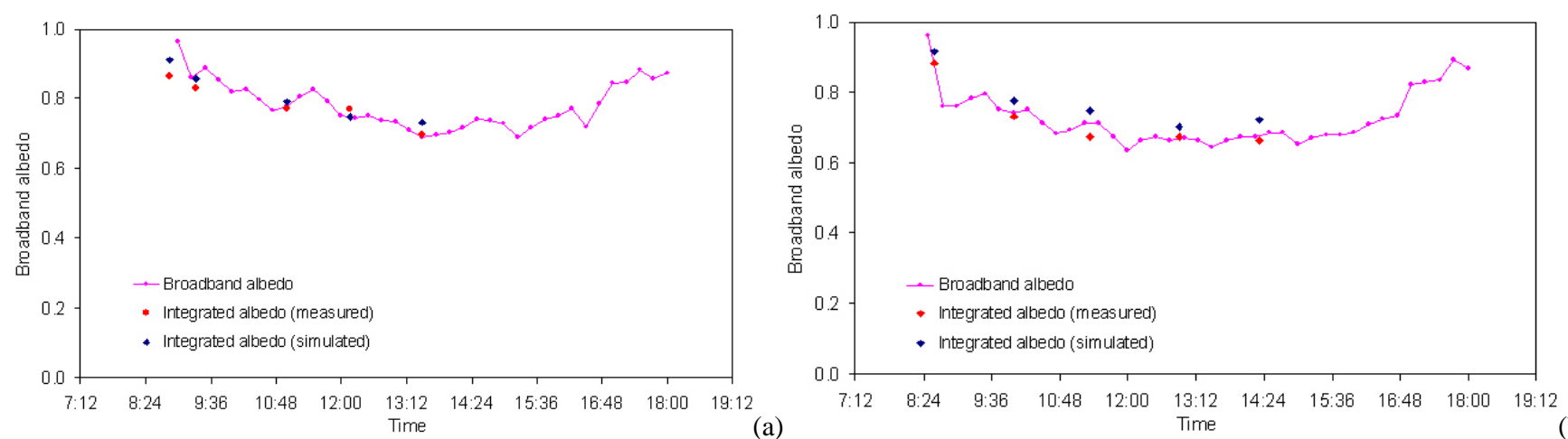

Fig. 7. The comparison between integrated albedo (measured: directly from field spectroradiomenter and, simulated: ART retrieved albedo from reflectance measurement) and field measured broadband albedo: (a) day 1 after snowfall 27 February 2006, (b) day 2 after snowfall 28 February 2006.
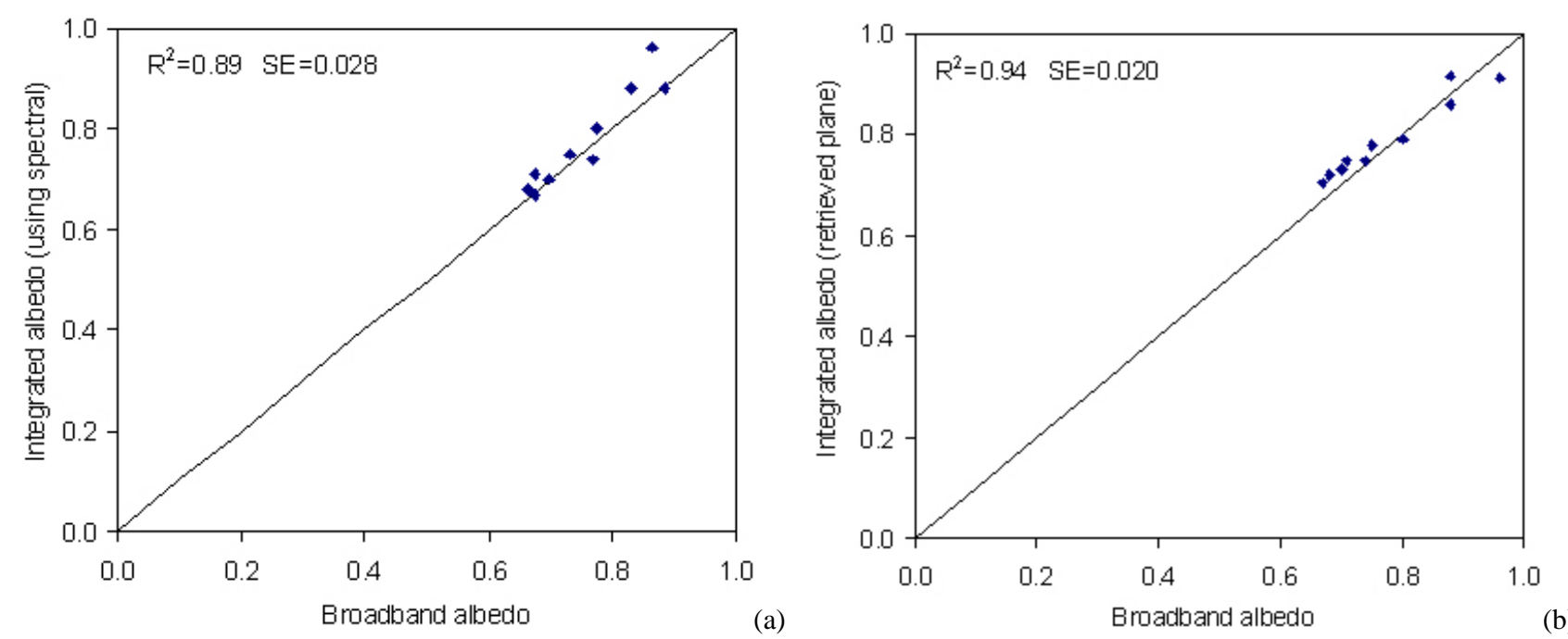

Fig. 8. The comparison between (a) broadband albedo and integrated albedo measured using spectroradiometer; (b) broadband albedo and simulated integrated albedo from reflectance measurement using the ART theory.
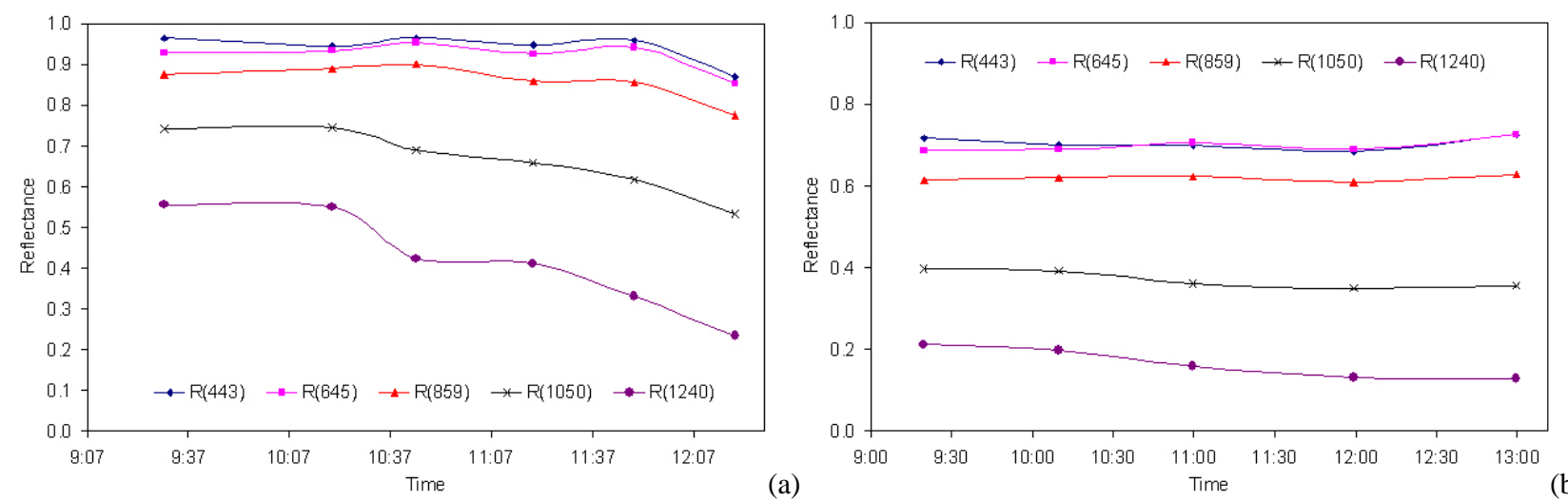

Fig. 9. Field measured reflectances of snow at wavelength 443, 645, 859, 1050 and $1240 \mathrm{~nm}$ (a) snow Type-I and (b) snow Type-II. 


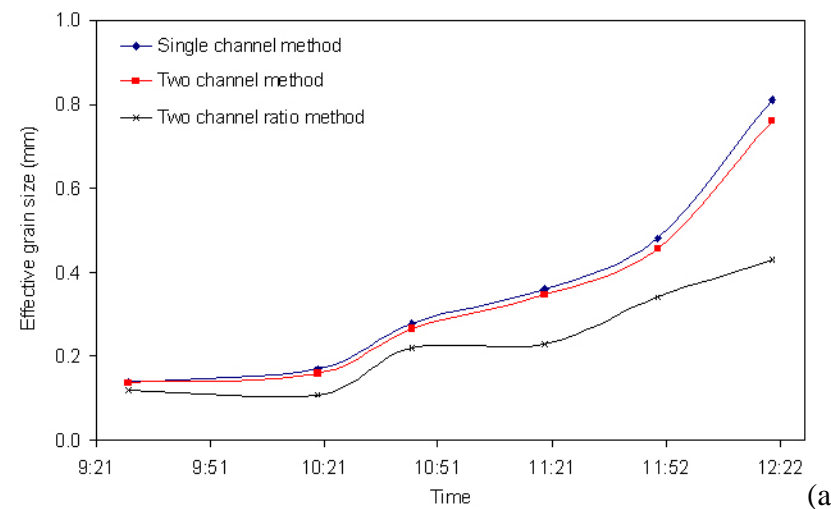

(a)

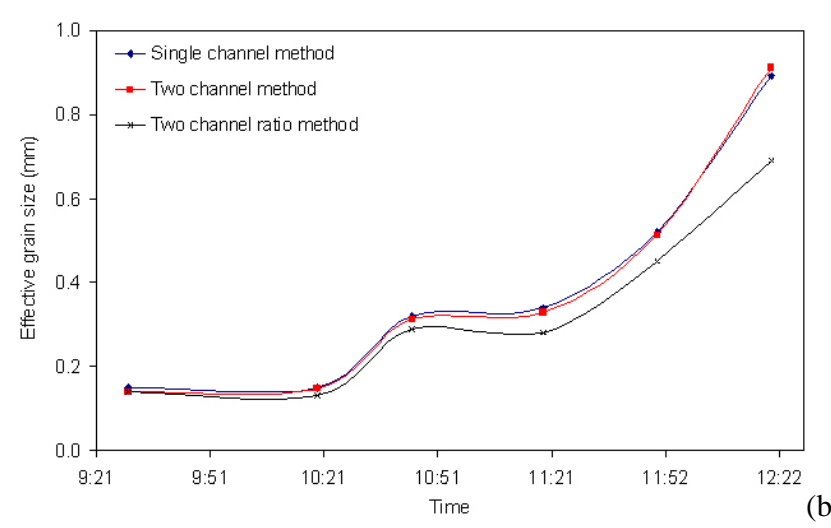

(b)

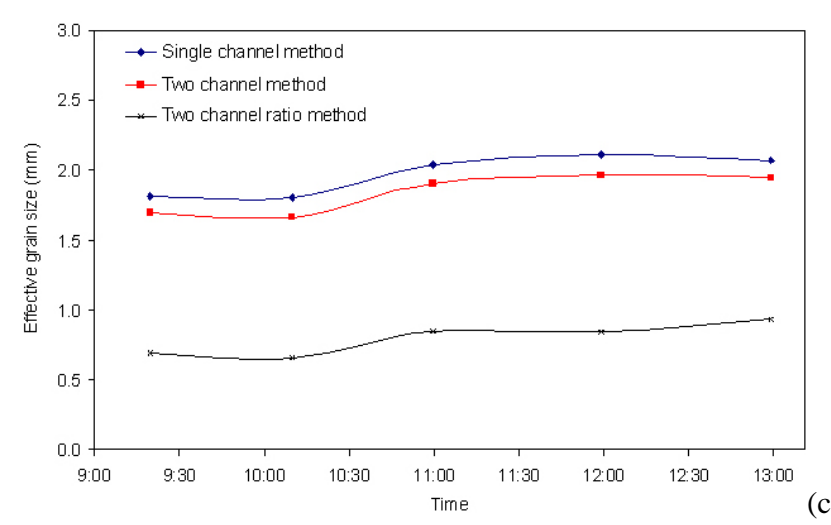

(c)

Fig. 10. Comparison of retrieved snow grain sizes; (a) snow TypeI using $1050 \mathrm{~nm}$ channel; (b) snow Type-I using $1240 \mathrm{~nm}$ channel and (c) snow Type-II using $1050 \mathrm{~nm}$ channel.

one (snow Type-II). Larger grain sizes were retrieved using the three channel method and found to be much more sensitive to the difference between reflectance observed in visible and NIR region. Since one additional NIR channel $R_{3}$ was used in this method, we are not considering this method by comparing it to other models where only one NIR channel was used to retrieve the grain sizes.

From Table 2 and Fig. 10, a good agreement can be observed between retrieved grain sizes with temporal increment using the single channel method and two channel method. However, a slight variation was observed using the two chan- nel ratio method. Almost similar grain sizes were retrieved using these three methods once the snow was new (snow type-I) with very fine grain and dry (snow surface temperature less than $0^{\circ} \mathrm{C}$ ). However, smaller grain sizes were retrieved using two channel ratio method as compared to two channel method once the snow metamorphosed (snow TypeII). This difference in retrieved grain sizes from other two methods attributed to the replacement of $R_{0}$ by visible channel reflectance $\left(R_{2}\right)$, where a large difference can be observed between $R_{0}$ and measured $R_{2}$. The deviation in retrieved grain sizes using three channel method with grain sizes retrieved from other methods may be due to the exclusion of $R_{0}$ using the visible channel. Therefore, the two channel ratio method or three channel method can work well for the snow covered area where the visible channel reflectance is high, like in polar regions or the upper Himalaya, but not for lower and middle Himalayan seasonal snow due to higher temperature and the proximity to habitat area. The single channel method and two channel method have a similar grain size trend with slight difference in sizes derived from $1.05 \mu \mathrm{m}$ for snow Type-I and Type-II (Fig. 10). This difference is due to the soot effect at $1.05 \mu \mathrm{m}$, which can be observed as negligible for channel $1.24 \mu \mathrm{m}$. Secondly, it was found that the grain sizes derived using the two channel method are more close to the ground-measured grain diameter, in comparison to grain size derived from the single channel method. Therefore, we propose the two channel method for various types of Himalayan seasonal snow.

The retrieved grain sizes using channel $1.05 \mu \mathrm{m}$ and $1.24 \mu \mathrm{m}$ for snow Type-I, using all the methods, showed linear relations for small grain sizes, i.e., early hours of the day (Fig. 11). However, this deviation is more for larger grain sizes, i.e., with respect to time, which indicate the presence of vertical inhomogeneity in the snowpack at late hours of the day, as wavelength $1.05 \mu \mathrm{m}$ penetrates more in snow than that at $1.24 \mu \mathrm{m}$. Ground snow cover information also supports the vertical inhomogeneity at later day time as the fresh snowfall produced only $10 \mathrm{~cm}$ of snow on existing snowpack, which become thin by the later hours and, thus, the variation in retrieved grain sizes was observed due to underlying old snow with different grain sizes.

Furthermore, the spherical and plane albedos can also be modelled using the ART theory once the effective grain diameter " $d$ " correctly estimated. The theoretical spherical albedo using grain size and the simulated spherical albedo from reflectance measurement for snow Type-I were observed well in agreement up to $1400 \mathrm{~nm}$ and for larger wavelength difference increased due to the limitation of the theory for large absorption (Fig. 12). But such good agreement between theoretical albedo and simulated albedo cannot be observed for snow Type-II, as the low reflectances in the visible region cause lower actual albedo. Therefore, one can retrieve the albedo from single channel in NIR using the ART theory for clean snow, but we suggest for the Himalayan-like seasonal snow the narrow band to broadband (NTB) albedo can 
Table 2. Retrieved snow grain size " $d$ " (i.e., $2 \times a_{\mathrm{ef}}$ ) using single channel method, two channel method, two channel ratio method and three channel method: $R_{1}, R_{2}, R_{3}, R_{4}$ and $R_{5}$ are the reflectance at channel $0.443,0.645,0.859,1.05$ and $1.24 \mu \mathrm{m}$, respectively.

\begin{tabular}{|c|c|c|c|c|c|c|c|c|c|}
\hline \multirow{2}{*}{$\begin{array}{l}\text { Snow type } \\
\text { and date of } \\
\text { observation }\end{array}$} & \multirow{2}{*}{$\begin{array}{c}\text { Time of } \\
\text { observation } \\
\text { (LT) }\end{array}$} & \multicolumn{2}{|c|}{$\begin{array}{l}\text { Grain size }(\mathrm{mm}) \text { using } \\
\text { single channel method }\end{array}$} & \multicolumn{2}{|c|}{$\begin{array}{l}\text { Grain size }(\mathrm{mm}) \text { using } \\
\text { two channel method }\end{array}$} & \multicolumn{2}{|c|}{$\begin{array}{l}\text { Grain size }(\mathrm{mm}) \text { using } \\
\text { two channel ratio method }\end{array}$} & \multicolumn{2}{|c|}{$\begin{array}{l}\text { Grain size }(\mathrm{mm}) \text { using } \\
\text { three channel method }\end{array}$} \\
\hline & & $R_{4}$ & $R_{5}$ & $R_{1}, R_{4}$ & $R_{1}, R_{5}$ & $R_{2}, R_{4}$ & $R_{2}, R_{5}$ & $R_{2}, R_{3}, R_{4}$ & $R_{2}, R_{3}, R_{5}$ \\
\hline \multirow{6}{*}{$\begin{array}{l}\text { Type-I snow } \\
29 \text { January } 2005\end{array}$} & $09: 30$ & 0.14 & 0.15 & 0.14 & 0.14 & 0.12 & 0.14 & 0.33 & 0.37 \\
\hline & $10: 20$ & 0.17 & 0.15 & 0.16 & 0.15 & 0.11 & 0.13 & 0.35 & 0.30 \\
\hline & $10: 45$ & 0.28 & 0.32 & 0.27 & 0.31 & 0.22 & 0.29 & 0.94 & 0.87 \\
\hline & $11: 20$ & 0.36 & 0.34 & 0.35 & 0.33 & 0.23 & 0.28 & 0.72 & 0.65 \\
\hline & $11: 50$ & 0.48 & 0.52 & 0.45 & 0.51 & 0.34 & 0.45 & 1.07 & 1.14 \\
\hline & $12: 20$ & 0.81 & 0.89 & 0.76 & 0.91 & 0.43 & 0.69 & 1.34 & 1.80 \\
\hline \multirow{5}{*}{$\begin{array}{l}\text { Type-II snow } \\
19 \text { February } 2008\end{array}$} & 09:20 & 1.81 & - & 1.70 & - & 0.69 & - & 1.64 & - \\
\hline & $10: 10$ & 1.80 & - & 1.66 & - & 0.66 & - & 1.67 & - \\
\hline & 11:00 & 2.04 & - & 1.91 & - & 0.85 & - & 2.28 & - \\
\hline & $12: 00$ & 2.11 & - & 1.96 & - & 0.84 & - & 2.26 & - \\
\hline & $13: 00$ & 2.07 & - & 1.95 & - & 0.94 & - & 2.43 & - \\
\hline
\end{tabular}

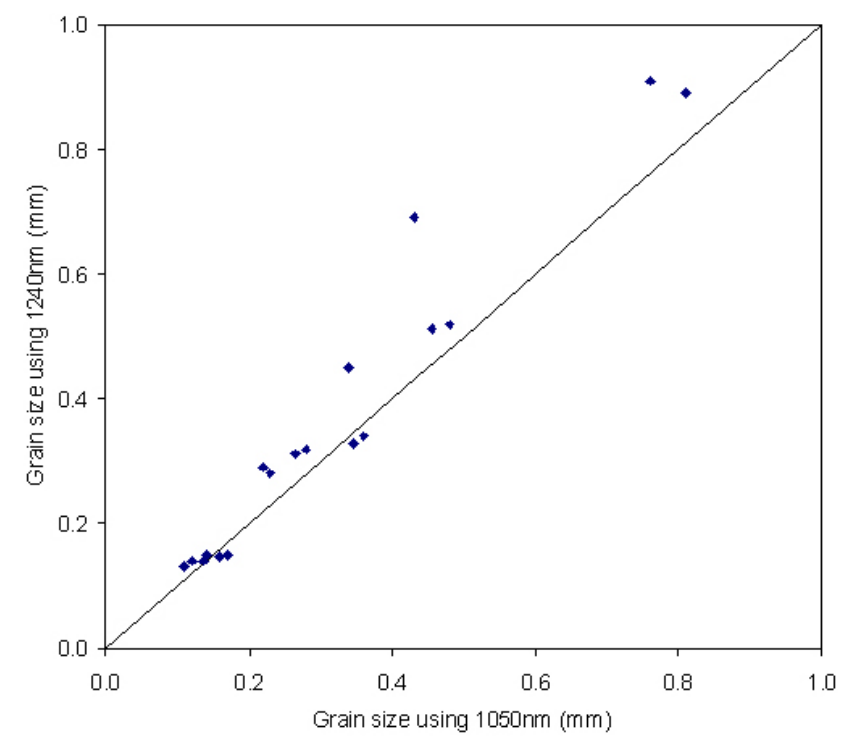

Fig. 11. Retrieved grain sizes using channel 1050 and $1240 \mathrm{~nm}$ for snow Type-I.

work better for albedo estimation from space, where narrow band (spectral) albedo can be retrieved from reflectance as discussed in Sects. 4.1. and 5.1.

\section{Conclusions}

The main advantage of the ART theory is the analytical solutions of the radiative transfer theory for retrieving the snow properties. This makes it possible to perform fast retrievals instead of running radiative transfer codes. Therefore, this technique can be used to generate the operational snowcover grain size and albedo maps using air-borne or space-borne

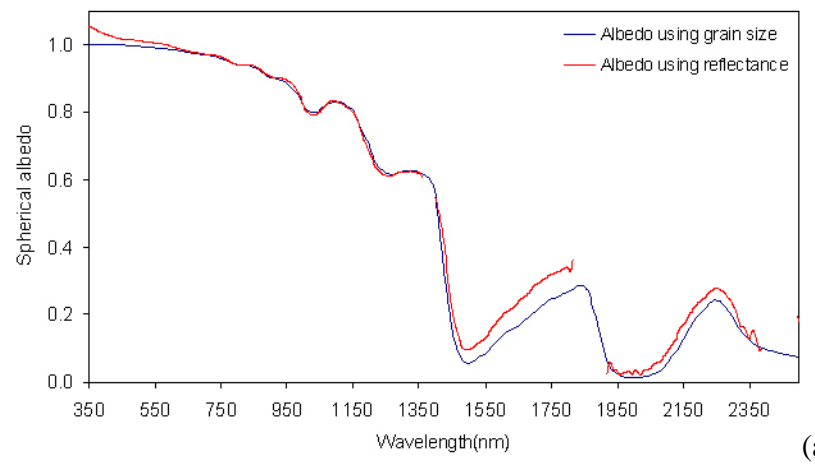

(a)

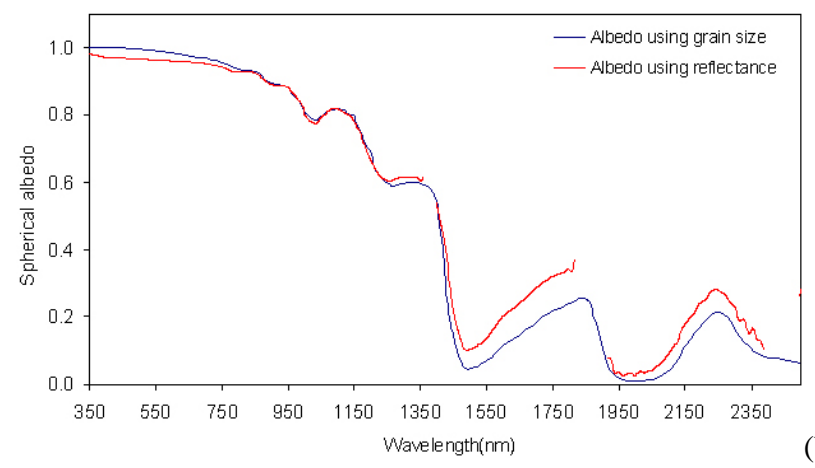

(b)

Fig. 12. The comparison between spherical albedo simulated using grain size (using two channel model) and simulated from the reflectance measurements for snow Type-I (a) 09:30 and (b) 10:20 local time.

mutispectral sensor data. Before directly applying the theory to retrieve the snow properties from satellite data of the $\mathrm{Hi}$ malayan region, it was an important step to understand how it behaves for the different types of seasonal snow.

With this study, it was found that the ART theory can work well for simulating seasonal snow albedo (i.e., plane 
and spherical) from the reflectance. This is also an important input for retrieving narrow band to broadband albedo. The comparison of retrieved grain sizes using different models for different types of snow helped in understanding the advantage and limitations of these methods for the Himalayan region. The two channel method was found suitable for all the types of snow studied. In this method, any one NIR channel $(0.865 / 1.05 / 1.24 \mu \mathrm{m})$ along with visible channel $(0.443 \mu \mathrm{m})$ can be used which can accommodate the absorption in NIR channel due to the presence of soot. The other grain size methods using directly visible channel reflectance for $R_{0}$ to retrieve grain sizes are found sensitive to visible snow reflectance and such models are inconsistent for retrieving the grain sizes. The detection of vertical inhomogeneity within the snowpack using grain retrievals by different ice absorption channels can be very helpful in snow avalanche studies of the Himalayan region to find the stability of the snowpack.

Acknowledgements. H. S. Negi thanks to Snow \& Avalanche Study Establishment (SASE), DRDO, India for supporting all the field investigations, and Department of Science and Technology (DST), India for providing BOYSCAST fellowship to this work. A. Kokhanovsky thanks ESA (Snow-Radiance Project) and JAXA (SGLI Cryosphere Project) for support of this research. He also acknowledges the support of the BMBF Project CLIMSLIP. The authors are grateful to J. B. Burrows, IUP, University of Bremen, Germany, A. Ganju, SASE, Chandigarh, India and A. V. Kulkarni, IISc. Bangalore, India for support and discussions.

Edited by: S. Dery

\section{References}

Analytical Spectral Devices: Fieldspec TM, Technical Guide, 3rd edn. (Boulder, Co), USA, 1999.

Aoki, T., Aoki, T., Fukabori, M., Hachikubo, A., Tachibana, Y., and Nishio, F.: Effects of snow physical parameters on spectral albedo and bi-directional reflectance of snow surface, J. Geophys. Res., 105(D8), 10219-10236, 2000.

Aoki, T., Hachikubo, A., and Hori, M.: Effects of snow physical parameters on shortwave broadband albedos, J. Geophys. Res., 108(D19), 4616, doi:10.1029/2003JD003506, 2003.

Bohren, C. F. and Barkstrom, B. R.: Theory of the optical properties of snow, J. Geophys. Res., 79(30), 4527-4535, 1974.

Colbeck, S. C.: An overview of seasonal snow metamorphism, Rev. Geophys. Space Ge., 20, 45-61, 1982.

Domine, F., Albert, M., Huthwelker, T., Jacobi, H.-W., Kokhanovsky, A. A., Lehning, M., Picard, G., and Simpson, W. R.: Snow physics as relevant to snow photochemistry, Atmos. Chem. Phys., 8, 171-208, doi:10.5194/acp-8-171-2008, 2008.

Dozier, J., Green, R. O., Nolin, A. W., and Painter, T. H.: Interpretation of snow properties from imaging spectrometry, Remote Sens. Environ., 113, S25-S37, 2009.

Fily, M., Bourdelles, B., Dedieu, J. P., and Sergent, C.: Comparison of in situ and Landsat thematic mapper derived snow grain characteristics in the Alps, Remote Sens. Environ., 59, 452-460, 1997.
Hori, M., Aoki, T., Stamnes, K., Chen, B., and Li, W.: Preliminary validation of the GLI cryosphere algorithms with MODIS daytime data, Polar Met. Glacio., 15, 1-20, 2001.

Jin, Z., Charlock, T. P., Yang, P., Xie, Y., and Miller, W.: Snow optical properties for different particle shapes with application to snow grain size retrieval and MODIS/CERES radiance comparison over Antarctica, Remote Sens. Environ., 112, 3563-3581, 2008.

Kokhanovsky, A. A.: Statistical properties of a photon gas in random media, Phys. Rev., E66, 1-4, 2002.

Kokhanovsky, A. A.: Polarization optics of random media, Springer, Dordrecht, U.K., 2003.

Kokhanovsky, A. A.: Cloud optics, Springer-Praxis, Chichester, Netherlands, 2004a.

Kokhanovsky, A. A.: Spectral reflectance of whitecaps, J. Geophys. Res., 109, C05021, doi:10.1029/2003JC002177, 2004b.

Kokhanovsky, A. A.: Reflection of light from a semi-infinite medium with irregularly shaped particles, J. Quant. Spectrosc. Ra., 96, 1-10, 2005.

Kokhanovsky, A. A., Rozanov, V. V., Zege, E. P., Bovensmann, H., and Burrows, J. P.: A semi-analytical cloud retrieval algorithm using backscattering radiation in $0.4-2.4 \mu \mathrm{m}$ spectral range, J. Geophy. Res., 108(D1), 1-19, 2003.

Kokhanovsky, A. A. and Nauss, T.: Satellite based retrieval of ice cloud properties using semianalytical algorithm, J. Geophy. Res., 110, D19206, doi:10.1029/2004JD005744, 2005.

Kokhanovsky, A. and Sokoletsky, L. G.: Reflection of light from semi-infinite absorbing turbid media, part 1: spherical albedo, Color Res. Appl., 31(6), 491-497, 2006.

Kokhanovsky, A. and Schreier, M.: The determination of snow specific surface area, albedo and effective grain size using AATSR space-borne measurements, Int. J. Remote Sens., 30(4), 919933, 2009.

Kokhanovsky, A. A. and Zege, E. P.: Scattering optics of snow, Appl. Optics, 43(7), 1589-1602, 2004.

Kokhanovsky, A. A., Aoki, T., Hachikubo, A., Hori, M., and Zege, E. P.: Reflective properties of natural snow: approximate asymptotic theory versus in situ measurements, IEEE T. Geosci. Remote S., 43(7), 1529-1535, 2005.

Kokhanovsky, A., Mayer, B., von Hoyningen-Huene, W., Schmidt, S., and Pilewskie, P.: Retrieval of cloud spherical albedo from top-of-atmosphere reflectance measurements performed at a single observation angle, Atmos. Chem. Phys., 7, 3633-3637, doi:10.5194/acp-7-3633-2007, 2007.

Kokhanovsky, A. A., Rozanov, V. V., Aoki, T., Odermatt, D., Brockmann, B., Kruger, O., Bouvet, M., Drusch, M., and Hori, M.: Sizing snow grains using backscattered solar light, Int. J. Remote Sens., in press, 2011.

Legagneux, L., Cabanes, A., and Domine, F.: Measurement of the specific surface area of 176 snow samples using methane adsorption at 77 K, J. Geophys. Res., 107(D17), 4335, doi:10.1029/2001JD001016, 2002.

Li, W., Stamnes, K., Chen, B., and Xiong, X.: Snow grain size retrieved from near-infrared radiances at multiple wavelengths, Geophy. Res. Lett., 28, 1699-1702, 2001.

Liu, J., Schaaf, C., Strahler, A., Jiao, Z., Shuai, Y., Zhang, Q., Roman, M., Augustine, J. A., and Dutton, E. G.: Validation of moderate resolution imaging spectroradiometer (MODIS) albedo retrieval algorithm: Dependence of albedo on solar zenith angle, J. 
Geophys. Res., 114, D01106, doi:10.1029/2008JD009969, 2009.

Lyapustin, A., Tedesco, M., Wang, Y., Aoki, T., Hori, M., and Kokhanovsky, A.: Retrieval of snow grain size over Greenland from MODIS, Remote Sens. Environ., 113, 1976-1987, 2009.

Massom, R. A., Eicken, H., Haas, C., Jeffris, M. O., Drinkwater, M. R., Sturm, M., Worby, A. P., Wu, X., Lytle, V. I., Ushio, S., Morris, K., Reid, P. A., Warren, S. G., and Allison, I.: Snow on Antarctic ice, Rev. Geophys., 39, 413-445, 2001.

Matzl, M.: Quantifying the stratigraphy of snow profiles, Ph.D. thesis, Swiss Federal Institute of Technology, Zurich, 2006.

Matzl, M. and Schneebelli, M.: Measuring specific surface area of snow by near-infraref photography, J. Glaciol., 52(179), 558564, 2006.

Milton, E. J.: Principles of field spectroscopy-Review Article, Int. J. Remote Sens., 8(12), 1807-1827, 1987.

Milton, E. J., Schaepman, M. E., Anderson, K., Kneubühler, M., and Fox, N.: Progress in field spectroscopy, Remote Sens. Environ., 113, 92-109, 2009.

Mishchenko, M. I., Dlugach, J. M., Yanovitskij, E. G., and Zakharova, N. T.: Bidirectional reflectance of flat, optically thick particulate layers: an efficient radiative transfer solution and applications to snow and soil surfaces, J. Quant. Spectrosc. Ra., 63, 409-432, 1999.

Mishchenko, M. I., Travis, L. D., and Lacis, A. A.: Absorption, scattering, and emission of light by small particles, Cambridge U. Press, Cambridge, 2002.

Negi, H. S., Kulkarni, A. V. and Semwal, B. S.: Study of contaminated and mixed objects snow reflectance in Indian Himalaya using spectroradiometer, Int. J Remote Sens., 30(2), 315-325, 2009.

Nolin, A. W. and Dozier, J.: Estimating snow grain size using AVIRIS data, Remote Sens. Environ., 44, 231-238, 1993.
Painter, T. H., Molotch, N. P., Cassidy, M., Flanner, M., and Steffen, K.: Instruments and methods contact spectroscopy for determination of stratigraphy of snow optical grain size, J. Glaciol., 53(180), 121-127, 2007.

Schneebeli, M. and Sokratov, S. A.: Tomography of temperature gradient metamorphism of snow and associated changes in heat conductivity, Hydrol. Process., 18, 3655-3665, 2004.

Sharma, S. S. and Ganju, A.: Complexities of avalanche forecasting in Western Himalaya - an overview, Cold Reg. Sci. Technol., 31, 95-102, 2000.

Tedesco, M. and Kokhanovsky, A. A.: The semi-analytical snow retrieval algorithm and its application to MODIS data, Remote Sens. Environ., 110, 317-331, 2007.

Wang, X. and Zender, C. S.: MODIS snow albedo bias at high solar zenith angles relative to theory and to in situ observations in Greenland, Remote Sens. Environ., 114, 563-575, 2010.

Warren, S. G.: Optical properties of snow, Rev. Geophys. Space Ge., 20(1), 67-89, 1982.

Warren, S. G. and Brandt, R. E.: Optical constant of ice from the ultraviolet to the microwave: A revised compilation, J. Geophy. Res., 113, D114220, doi:10.1029/2007JD009744, 2008.

Warren, S. G. and Wiscombe, W. J.: A model for the spectral albedo of snow-II: snow containing atmospheric aerosols, J. Atmos. Sci., 37, 2734-2745, 1980.

Warren, S. G., Grenfell, T. C., and Mullen, P. C.: Optical properties of Antarctic snow, Antarct. J. US, 21, 247-248, 1986.

Wiscombe, W. J. and Warren, S. G.: A model for the spectral albedo of snow-I: pure snow, J. Atmos. Sci., 37, 2712-2733, 1980.

Zege, E., Katsev, I., Malinka, A., Prikhach, A., and Polonsky, I.: New algorithm to retrieve the effective snow grain size and pollution amount from satellite data, Ann. Glaciol., 49, 139-144, 2008. 